\title{
AUGUSTINE: THE READER AS SELFOBJECT
}

\author{
VOLNEY GAY*
}

\section{INTRODUCTION}

$\mathbf{I}_{\mathrm{t}}$ is difficult to resist books with the title of "confession." Will its author confess to the world of those actions and thoughts that shame us most and so ameliorate our suffering? Following Augustine's great book, similar accounts by Rousseau (1781-1788), Goethe (1811-33), Gide (1889-1949, [1967]), and others have earned a place in literature. The number of non-confessional autobiographies is immense: Kaplan (1961) lists more than 6,000 titles by Americans alone. Regardless of their literary merits, autobiographies have an additional narcissistic value. Our own needs to feel worthwhile and unique are satisfied, in a roundabout way, when we compare ourselves and these sublime masters. Yet confession maintains their luster since they have felt their inner life was worth reporting to the masses, while few of us could muster that belief. To this point, Freud's masterpiece, The Interpretation of Dreams (1900) achieves authority precisely because it contains so many "confessions." It reveals Freud's jealous, petty, sexualized, and hostile wishes, his grandiose ambitions, and his severe neuroticisms. In other words, it reveals a person much like ourselves, the difference being that Freud and Augustine created intellectual modes that permit confession but prevent narcissistic abasement.

Henri Ellenberger (1970) persuades me that much of Freud's influence stems from his enormous literary talents. His first dream, "Irma's Injection," requires seventeen pages of dense interpretation (and has been re-interpreted numerous times since). It is his dream; it deals with his most private feelings, his hopes, his wishes, and his characteristic defenses, including an ignoble attempt to cover up his friend's medical errors. Freud's text operates much like Confessions: an inherently personal story, one's dreams, or one's conversion, are made public and, via literary genius, transformed into authoritative wisdom.

Reading Confessions, even some fifteen centuries after its composition and in translation, is no mere intellectual moment. I feel it is closer to being confronted by an impassioned speaker who is not above grabbing one by the lapels in order to force his message home. This is not always a comfortable experience. However, it does suggest that Augustine wrote Confessions out of many complex motives. Some of these he states overtly: to indicate the power of God's intervention, to demonstrate human folly, and to articulate a coherent theology that would counteract the pull of Manichaeism. Others are less manifest and must be inferred. TeSelle (1970) and other scholars describe some of the difficulties in assessing clearly all of Augustine's intentions. He notes that Confessions argues consistently that God alone provides Augustine a sense of the coherence of "his life in the past, present, and future" (191).

\footnotetext{
-Volney Gay is Associate Professor in Religious Studies and Psychiatry at Vanderbilt University Nashville. Tennessee.
} 
That makes sense to me, and I believe it accounts for my experience of being pulled into the text, as a member of Augustine's audience. Augustine's fundamental need to establish a sense of coherence underlies his use of the reader. To clarify what this means in contemporary psychoanalytic parlance, I explicate some key concepts in current work on narcissism, particularly the concept of selfobject (in earlier texts written self-object).

My general thesis is that Confessions is written for an audience which Augustine uses as selfobjects. That is, we, his imagined audience, are a crucial, underlying element in his work and our (imagined) responses help him reconstitute himself, to feel coherent in time and space. This "narcissistic" reading of the text, following Kohut and Winnicott, suggests that the earlier oedipal interpretations of Confessions overemphasized issues of sexual conflict and therefore the basic anxiety which Confessions was meant to solve.

I do not formulate a diagnosis of Augustine's personality. Since the Confessions covers most of Augustine's life, it would be difficult to know exactly which portion one felt represented something like his essential character. I would rather emphasize the profound devaluation of narcissistic needs which animates the whole of Augustine's account. It parallels Freud's unanalytic denunciation of narcissism. What is denied and suppressed must, Freud taught us, reappear in a disguised form as symptoms and alienation. Confessions was Augustine's solution to his culture's denunciation of narcissistic needs. Universal needs to feel esteemed and loved by a wholly good object reemerged in his theology and in his grand, public confessions. The grandeur and splendor of Augustine's self-denunciations betray precisely a split self, one part identifying with the Lord who judges everyone with infinite demands, the other part contrite petitioner. His would be a confession to God and to humans at the same time. It would gain him God's forgiveness and so union with Him, and an audience of readers who would mirror back to him their esteem.

To clarify these points I first distinguish oedipal anxieties from pre-oedipal anxieties. I then define the concept of selfobject relationship, and try to show that Confessions contains Augustine's covert plea for selfobject relationships with both God and his readers. Finally, I suggest that the hypersexualization which occurs throughout Augustine's account are unconscious attempts to undo fragmentation experiences. They occur when he attempts to repair rents in his selfesteem, concentrating himself within hypersexualized experiences whose intensity guaranteed their importance. Both Augustine and Freud view such eruptions of sexuality as breakthroughs of repressed, primal instincts. Augustine calls them inherently sinful. Freud eschews such moralism, but retains the metaphysical assumption that they represent the outbreak of something immensely powerful and beyond the ego's control. Kohut's reevaluation of narcissistic needs and their fulfillment in selfobject relationships offers an account of such sexualization that is less moralistic than Augustine's own. (All references to Confessions are from Pine-Coffin's 1961 translation.)

\section{OEDIPAL ANXIETIES AND SELF ANXIETIES}

Oedipal theory describes triadic relationships between distinct actors: mother, father, and child. It illuminates the child's struggles to feel manly or womanly compared to others, like one's parents, who are more powerful, more "manly" or "womanly" than the child. The great unconscious symbols of such struggles therefore revolve around genitals (penis 
envy, castration anxiety, etc.) and their fate as the dominant signs of difference and power. Who is big and who is little? Who has authority over whom? Oedipal conflicts occur between whole persons who feel vulnerable to damage (to being wounded or hurt or diminished) by other, whole persons who will respond to one's demand for authority with vengeance. The distinguished authors of the first essays in JSSR took this route when they analyzed Confessions as dealing with Augustine's conflicts over sexuality and aggression. How did his idealized and absolutist mother affect his sexual life? How should we understand the disdain Augustine shows for his biological father, and how does that fit into his adoration of the Divine Father? I think these are excellent questions. Aside from Bakan's hostile comments, the previous JSSR pieces, especially that of Dittes (1965), articulate well this level of Augustine's life.

To these oedipal level readings we can add a pre-oedipal analysis. Toward the end of his life Freud realized the next great task of his science was to investigate pre-oedipal history, that is, the child's experiences and traumas prior to the formation of a whole and complete self. With the broadening scope of analysis beyond neurotic patients, to the treatment of children, psychotoc persons, and other patient populations, analytic theory has expanded to encompass these dynamics as well. At that level of work, one finds that the fundamental anxieties are not castration (or its many variants). Rather they center around the infant's needs to receive mothering from a person whose ministrations and empathy resonate with the infant.

Among those primary needs is the infant's requirement to be held internally and externally. Using adult metaphors, we may say that the empathic parent contains the infant's experience of self. The empathic parent does those things, like regulate selfesteem, which will come gradually under the control of the child's internal world, his or her ego. The famous "gleam in the mother's eye" is a nice, if homely, example of precisely such holding: she reflects back to her child the child's own need to feel special. Children whose parents realize that this is the "bestest baby in the world" receive such holding and are better for it. Those who do not, whose parents have a "realistic" assessment of their child, cannot reflect back and so validate the child's fundamental need to feel worthy of existence. Hence such children live in a constant state of narcissistic tension.

Oedipal anxieties are experienced as external attacks upon bodily integrity. Hence oedipal anxieties utilize metaphors of external harm to a treasured body-part, like the eyes or the genitals. The dominant imagery of oedipal conflicts, for example in fairy tales and dreams, centers around the fate of a highly cathected aspect of the body: losing or gaining a penis. Freud elucidated basic theorems of castration anxiety and penis envy in his neurotic patients whose conflicts he analyzed at this level of development.

Pre-oedipal anxieties emerge as internal attacks upon the self, either from a persecutor, like the Wicked Witch, or through unbearable feelings of worthlessness. Fantasies that one's mind is dissolving, that one's body is made of soap or some other substance that might disappear, or that one is turning into a machine (Tausk, 1919) dominate pre-oedipal pathology. A colleague described a middle-aged patient who felt that his feet, legs, and torso were changing sequentially from flesh into metal. When this transformation reached the patient's head the psychosis was complete.

Pre-oedipal anxieties are often variations of "Humpty Dumpty." As we know, Humpty took a great fall and no one could put him together again. Kohut terms such fears 
fragmentation anxiety. It appears directly in the psychotic's fear of going to pieces and in severely traumatized children. Since everyone was first an infant, then a child, and so on, everyone will have faced and mastered to some degree or another these fundamental anxieties. Like castration anxiety, fragmentation anxiety defines one dimension of the human condition. Hence, like castration anxiety, great cultural institutions, including religion, have addressed fragmentation anxiety and in many ways contained it.

Western religionists contain it by articulating a portrait of a deity who knows one's deepest thoughts, is part of our fabric (are we not made in God's image?), and will not permit us to fall out of the world into nothingness. Unlike the poor astronaut in the film 2001: A Space Odyssey, we cannot be separated from God's love.

Because fragmentation anxiety is ubiquitous and intolerable, humans avoid it at all costs. Good-enough mothering accomplishes that task for the infant, and good-enough parenting for the child. Infant and child turn towards loving adults who will provide those ego functions of synthesis and coherence that are not yet within the infant's purview. In theological terms, good-enough parents instill hope. In psychoanalytic terms, they act as selfobjects, as persons who perform internal functions for an ego still forming.

But what about adults? Should we not outgrow such needs and such relationships? Is not maturation precisely as Freud said it was: to forsake neurotic fantasy solution for actual, inexact and imperfect real solutions? Again, in contrast to Freud's basic stance. Kohut argues that no person is immune to the need for others to fulfill these "selfobject" functions throughout the lifespan. Happy adults will be neither as needy nor as vulnerable as infants, but they will require selfobjects just as they require food and water.

Kohut and Freud do not share a common valuation of such needs. This bespeaks a profound difference in scientific outlook. Freud views castration anxiety as the ego's weak response to powerful drives the intensity of which threatens the ego. With ego development comes an increased capacity to battle against those drives and their associated wishes. Hence in a real sense neurotics of all ages misperceive their actual situation: they are childish and afraid of childish forces that now cannot overwhelm them as they once did.

In contrast, Kohut asserts that persons always need selfobjects. Hence, fragmentation anxiety in very sick patients is not a misperception or a carryover from an infantile past that will dissolve upon analysis. On the contrary, healthy adults will recognize that they too need others, both as whole objects and as selfobjects, that is, as persons who can help "hold" the self together. In drive theory terms, selfobjects are persons who act on the side of the "ego instincts" that aim at survival. In more phenomenological terms they share, momentarily, our deepest narcissistic feelings that our unique self is worthy of living, of being whole and powerful. From the outside such needs may appear as grandiose and irrational. From the inside (Kohut, 1959) they feel equivalent to our desire to breathe. In a telling metaphor, Kohut refers to the "psychological oxygen" which selfobjects give us $(1977,1984)$. To deny the validity of such needs, on the grounds of "objectivity," for example, is equivalent to demanding that a person drowning in high seas calm down and learn to breathe water.

We would expect such demands to elicit a great deal of rage. They do. Failures to salute a colleague, or cite their work, gains one lifelong enemies. Kohut (1972) elaborates the varieties of narcissistic rage along a continuum that extends from momentary anger at being snubbed to the extended and deep anger that dominates many borderline patients 
who feel misheard and misperceived. (A typical history of such patients shows a depressed mother whom the child struggled to revive in order that she might then reflect back to the child the child's sense of worth.)

Like Freud, Kohut's discoveries occurred in the field of analytic treatment of psychic suffering ("mental illness"). Like Freud, Kohut realized quickly that his narrow discoveries were relevant to larger, non-pathological realms, including religion. However, unlike Freud, Kohut does not view his discoveries as metaphysical competitors with traditional ontologies. Freud knew there was no God, and he drafted his clinical theories into philosophic refutations of all those who believed otherwise. Kohut does not leap from clinical theory to metaphysics this way.

This has an important consequence for humanists familiar with reductive readings of great texts done under the guise of "applied analysis." While one may count many brilliant examples of such applications, beginning with Freud's comments on Oedipus Tyrannus, many more are disappointing. Why would it be otherwise? Since the genius of psychoanalysis is an observational, empathic science of actual behavior, utilizing its terms, abstracted from their home in clinical practice, forfeits that genius. More importantly, applications of the classical theory tend to be written from on high, without interacting with the text. Basic clinical values, like neutrality and abstinence, seem to support this stance. Kohut's theory and his innovations in technique counterbalance these classical points of view. First, by grounding analytic work upon empathic immersion in the other's world, he places the center of gravity, not in the analyst's perceptions of reality, but in the interactional field that exists between patient and analyst. Second, his core concept of selfobject requires the analyst to comprehend the patient through the patient's effect on the analyst's interior life. Hence, by definition, the analyst cannot assume a stance outside of, and certainly not superior to, the patient.

No analyst would dare interpret a dream without the patient's continuous cooperation. ideally with as little defense as possible. Yet applied analyses of static works of art are never dialogical. The novel, the painting, and Confessions cannot respond, cannot correct, and cannot deepen the initial interpretation (Wisdom, 1967).

At a more profound level, to the degree one is removed by time, culture and language from one's subject, one has fewer and fewer resources with which one could generate an empathic response. For Kohut this is the first order of business. Should the analyst fail to establish a semblance of empathic understanding, all subsequent formulations will be extraneous to the deep need of the other to be understood: "Concretely speaking, whenever a patient reacts with rage to the anlyst's interpretations, he has experienced him, from the point of view of the archaic self that has been activated in analysis, as a nonempathic attacker of the integrity of his self" (Kohut, 1977: 91). Consequently, while many, if not most, members of the text's customary home, say, theology, feel aggrieved by applied analyses, analysis itself suffers a similar distortion.

Having protested that, I plunge ahead and describe Confessions as a selfobject generated by Augustine to consolidate a newly won sense of coherence. Since everyone needs selfobjects throughout their lives, this is not pathologizing the text. On the contrary, it may help us understand why we find it necessary to revive Augustine's ideal image again and again, especially on anniversary occasions like this. 


\section{CONFESSIONS AS PLEA FOR SELFOBJECT RELATIONSHIP}

Confessions illuminates a great mind interrogating itself and demanding a response from both God and humans. Augustine touched on this theme only to reject it in Book 10: "Why, then, does it matter to me whether men should hear what I have to confess, as though it were they who were to cure all the evil that is in me?" (208). His theological answer is that if his readers share his own striving after charity, they will discern the truth of his account: "But charity believes all things - all things, that is, which are spoken by those who are joined as one in charity - and for this reason I, too, O Lord, make my confession aloud in the hearing of men" (208). This capacity for charity would seem to derive from the noblest portion of human being, the soul, which is the "better part of me because it animates the whole of my body. It gives it life, and this is something that no body can give to another body. But God is even more. He is the Life of my soul" (213). How can we know God? Only through the soul and its unique capacity to interrogate its memories and its "vast cloisters" (215). It is the "great force of life in living man, mortal though he is"! (224).

Confessions rings with Augustine's great pleasure in recalling his past, even the errors of his youth. While one cannot doubt his sincerity, neither can one doubt the tremendous intellectual pleasure he gained in composing the account. His denunciations of ordinary boyish pranks, for example, are far grander and more eloquent than the deeds warrant. Of course, he could not say that, since it would amount to another sin, intellectual pride, which, in turn, would have to be punished. This obsessional quality runs throughout Confessions, as it does throughout any account dominated by a superego as severe as Augustine's. (One thinks of the obsessive moralist who, having performed a good deed, takes pleasure in that fact and in turn recognizes that pleasure as a sin that must be punished, and then takes pleasure in that new bit of godliness, etc.)

In Kohut's terms, Augustine's unending self-analysis and his unending complaints about his moral failings derive from his repression of selfobject needs. Contrary to his manifest rejection of the pleasures of being read by mere mortals, Confessions represents a covert plea for selfobject relationships with an audience whose responses Augustine treasures deeply. Given his immense talents and a culture which seems to have offered every opportunity for self debasement, Augustine's struggles and solutions are remarkable. From Kohut's point of view, the young man's efforts to come to terms with his talents revolved around precisely narcissistic issues: how could he control himself and how channel his skills in ways that would restrain himself and keep his feet on the ground?

Confessions tells us his natural father was not equal to the task. Consequently, an extraordinaryily talented boy searched for other persons whom he could idealize and then trust with that task. In Kohut's terms, he needed to find suitable selfobjects. Hence he looked to Faustus, then Ambrose, and finally God, the most ideal of fathers. If it is God, not I, who commands such powers, then surely God will hear my confession, "because you first willed that I should confess to you, 0 Lord my God. For you are gracious, your mercy endures for ever" (253). 


\section{SELFOBJECT RELATIONSHIP IN CONFESSIONS}

Like other psychoanalytic theories of pre-oedipal development, expecially those dealing with the earliest events in the development of the self, Kohut's work rests upon a clinical premise most adults do not share: that human beings must construct slowly their understanding of themselves as whole, complete beings. Both common sense and traditional metaphysics assume that individuals are independent and coherent singularities. Although William James (1902) had described "subliminal selves" earlier, pre-oedipal theory systematically investigates the pathways that lead from relatively diffused, partial selves, to an adult sense of continuity and coherence. Erikson's basic propositions (1950) about ego identity and its pathological variants, especially identity diffusion, allude to a late manifestation of what Kohut terms self-pathology.

Contrary to common sense, "Selfobjects are objects which we experience as part of our self; the expected control over them is, therefore, closer to the concept of control which a grown-up expects to have over his own body and mind than to the concept of the control which he expects to have over others" (Kohut and Wolf, 1978: 414). Augustine wrote Confessions as an adult looking back towards his childhood. Lacking the concept of selfobject, he naturally interpreted infantile behavior toward others as identical to adult behavior. From that perspective, with its stringent superego, infantile needs for selfobject relationships will appear pathological (or sinful).

Yet, just as repressed sexual needs return in the form of symptoms, repressed narcissistic needs for selfobject merger return in adult life. These great needs, to feel worthy in oneself (an aspect of the "grandiose self"), and to feel bonded to an idealized other ("idealized parental imago"), cannot be ignored since they constitute the basic drive to attain and retain a sense of coherence. However, unlike sexual impulses which may take circuitous routes, including abstinence, Kohut argues that narcissistic yearnings are vital and require an actual, external, other for their fulfillment. This has led some of his critics to charge Kohut with environmentalism: that he ignores that traditional psychoanalytic empasis upon vicissitudes of unconscious fantasies.

An extreme critic might contend that he therefore ignores the patient's responsibility for his or her neurotic condition. This misses Kohut's point. Narcissistic wishes may be neuroticized and therefore distorted. But since they represent fundamental needs one cannot and should not hope to analyze them away. They are not, in other words, symptoms that will disappear upon correct interpretation. Hence, in one of his major papers, Kohut speaks about the transformation of narcissistic hopes, not their dissolution (1966). Needs to feel worthy, creative, and linked to a shared center of infinite value will not disappear

(Fowler, 1981). Analysis is thus a situation in which "the damaged self begins to strive to achieve or to re-establish a state of cohesion, vigour and inner harmony" (Kohut and Wolf, 1978: 414).

Erikson says of Luther, that if one has no psychology of the unconscious, one must have a theology of heaven and hell (1958). We may say the same about selfobject needs. If one's developmental psychology assumes that infants and children are wholly formed selves from the beginning, then the deep needs associated with the use of selfobjects will emerge as the work of a dark Power. They will seem extraordinary, uncanny and depersonalized. Hence, to control them the conscious self will necessarily call upon an 
equally uncanny and extraordinary power of Light.

\section{AUGUSTINE'S DEVELOPMENTAL PSYCHOLOGY}

Augustine agrees with the majority opinion when he speculates about infantile development in the first chapters of Confessions. Indeed, the harshness of his views suggests a strong reaction to precisely the needs for bonding, merger, and selfobject relationships that Kohut describes. His initial paean to God might equally well describe the infant's experience of the good-enough mother merged with her adoring child:

[S]ince nothing that exists could exist without you, does this mean that whatever exists does, in this sense contain you? If this is so, since I too exist, why do I ask you to come into me? ... I should be null and void and could not exist at all, if you, my God, were not in me. Or is it rather that I should not exist, unless. I existed in you? But if I exist in you, how can I call upon you to come to me? (22).

He solves this conundrum by envisioning God in ways which are strikingly female (even though he uses masculine nomenclature):

And when you pour yourself out over us, you are not drawn down to us but draw us up to yourself: you are not scattered away, but you gather us up. You fill all things, but do you fill them with your whole self? ... You support, you fill, and you protect all things. You create them, nourish them, and bring them to perfection (22-23).

He deepens this metaphor and at the same time shifts from a hymn to autobiography by linking God's infinite desire to love His creatures with his mother's breasts:

\footnotetext{
But neither my mother nor my nurses filled their breasts of their own accord, for it was you who used them, as your law prescribes, to give me infant's food. ... All this I have learned since then. because all gifts you have given to me, both spiritual and material, proclaim the truth of it. But in those days all I knew was how to suck, and how to lie still when my body sensed comfort or cry when it felt pain (25).
}

From our contemporary vantage point, it easy to see how Augustine misconstrues the infant's experience. He constantly anthropomorphizes infantile self-experience. Infants are basically adults who are very small, inarticulate, and consequently helpless. They are like foreigners in Gargantua: captives of superior, gigantic figures whose language they must comprehend slowly. Wittgenstein took Augustine to task for this theory of language (1958: 1-3). It shows equally well Augustine's unempathic view of infant psychology and the baby's inner world where the wishes are inside and no faculty can penetrate its mind. Since babies are miniature adults, according to this belief, they too sin and have faults which must be "rooted out" (27). Just as the capacity for signification is present from the beginning, infants are capable of gluttony and other sins.

At a manifest level, Augustine recognizes that these are speculations, based on his observations of infants and not part of his conscious memory. At the same time he wants to inculcate the truth of the doctrine of original sin (28). He attacks precisely those preoedipal yearnings that Kohut (and others) have designated as the crucial needs which must be satisfied before secondary structuralization can occur.

Augustine is not a patient, and his account is not a case report: it is a complex polemic, 
apology, and theological treatise. Yet it articulates a world view that is so inimical to Kohut's values it will pay to contrast his consistent condemnation of narcissistic wishes with Kohut's general theory.

In this light, Augustine's story of his boyhood sickness suggests a mother who shares the absolutist superego of her son, and perhaps the entire epoch. The boy is very sick; his mother fears for his life. She makes plans to have him baptized. But he recovers and "So my washing in the waters of baptism was postponed, in the surmise that, if I continued to live, I should defile myself again with sin, and after baptism, the guilt of pollution would be greater and more dangerous" (32).

This would seem to be the antithesis of an empathic view of childhood. In psychiatric parlance it suggests a world view that is radically paranoid: forces of evil inhabit everyone, including infants, and these must be met by forces of good. The ego is a weak, lonely hero struggling to align itself with the forces of good against the forces of evil. Augustine uses a beautiful metaphor that describes well this metapsychology: tides of temptation beat upon him who is yet "unmolded clay rather than upon the finished image which has yet received the stamp of baptism" (33).

This passage evokes the Genesis account of Yahweh, the potter who molded human beings into Yahweh's image (or eikon as the Septuagint expresses it). Yet it rejects that relative security by evoking also the evil effect floods of temptation may have upon weak and unformed characters.

Liquid metaphors appear throughout Augustine's account as they do in Freud's general account of the drives. Although separated by language and world view, both men conceive inner battles as struggles between upwelling, overwhelming, tides of eros. Augustine describes his sexual impulses as filthy lust, brewed in a cauldron of passion (52-53). Less poetically, Freud described the channels in the mind through which the libido flows, carving out an ever deepening bed of habit (1915). While he avoids moralizing about these currents of libido, Freud's basic stance toward them is identical to that of Augustine: one must acquire sufficient moral strength to overcome them. Augustine invoked God's power, while Freud, to our great advantage, de-escalated the issue to one of human proportions. Kohut's great contribution has been to advance this chain of moral reasoning (in the sense of moral philosophy).

Given Augustine's epoch, then, one can see the Confessions as an immense achievement. It elaborated a new intellectual achievement in the Socratic ideal of selfknowledge and self-control. It is not tendentious to point out that this is a narcissistic achievement in the sense that it permits Augustine to achieve a state of merger with an idealized Other who, in turn, can mirror his deepest hopes.

Many commentators have remarked upon Augustine's lack of empathy for his scholastic opponents and for his concubine. These are striking deficits, yet within that culture, indeed perhaps up to our century, one sees very few instances of any greater depth. To summarize a complex point, a culture that turns to transcendental solutions for selfobject needs will remain unempathic to the inner life of an individual. That is, transcendental solutions necessarily leap outside the individual's actual interior experience and invoke the authority of an idealized Wholly Other whose face is always obscure and intentions mysterious. According to this reading, therefore, Augustine's implacable selfaccusations are, as it were, reasonable attempts to make God mirror him, even if to 
condemn him. The incessant, compulsive quality of the Confessions derives, perhaps, from this profound need.

One might see the law of the return of the repressed operating with remorseless logic in the latter part of Confessions, where we read that Augustine continued to invoke a transcendental solution to his sexual conflicts. In his and Freud's psychologies, these struggles are eternal because the drives themselves are immortal powers that strive always to overthrow the ego's better judgment. Freud usually eschewed transcendental language. Yet such language appears when he describes the uncanny force the instincts exert upon the struggling ego, which must contend with these potentially immortal substances (Freud, 1920; 1921).

Freud's basic theorems about the two great instincts (or drives), eros and destructiveness, parallel Augustine's fascination with Manichaeism. It also describes human beings as battlegrounds over which two great powers struggle. Freud's preoccupation with the fate of these aggrandized and immortal substances parallels Augustine's struggle to shake off his fascination with Manichaeism.

Kohut counters both men's implicit metaphysics by tracing sexualization not to some fundamental drive that requires transcendental solution, but to deficits in a self-selfobject relationship:

Instead of the further development of a firmly cohesive self able to feel the glow of healthy pleasure in its affectionate and phase-appropriate sexual functioning and able to employ self-confident assertiveness in the pursuit of goals, we find thoughout life a continuing propensity to experience the fragments of love (sexual phantasies) rather than love, and the fragments of assertiveness (hostile fantasies) rather than assertiveness, and to respond to these experiences . . . with anxiety. (1984: 25, emphasis mine).

Parents, like Monica, who attend primarily to the control of these fragmentation products systematically deny that the child has a coherent and cohesive self. Kohut does not forget that sexualization and aggressivization mark a great deal of ordinary human experience. He does deny that these express the ultimate constituents of human nature, the bedrock of our animal natures which all honest persons must recognize. Augustine, like Freud, and like most Western moralists up to our times, increased this sense of fragmentation by taking for granted that sexual impulses, that "hissing cauldron of lust" (55), are irreducible forces which civilization must constrain, just as the Olympians jailed the Titans. Hence, when Augustine describes Alypius's backsliding into his earlier fascination with gladiatorial combat, he invokes again the metaphor of upwelling drives: "When he saw the blood, it was as though he had drunk a deep draught of savage passion. Instead of turning away, he fixed his eyes upon the scene and drank in all its frenzy, unaware of what he was doing" (122).

In contrast, Kohut views sexualization as a product of prior, narcissistic injury. Sexualized and aggressivized images, as well as perverse actions, are attempts to repair a wounded self.

Once a selfobject transference is established, the patient (or child) responds to alterations in it with fragmentation anxiety, which in turn elicits frantic, sexualized, efforts to repair the breach in self caused by that empathic failure. Given the subtleties and variety of selfobject transferences, empathic failures occur frequently. For example, some patients, like some children, may experience a two or three minute delay as sure signs of the analyst's 
disinterest. In response to that perception, they withdraw their deep wishes for merger with the analyst. Since that wish formed part of the armature, as it were, around which they wound their psychic structure, withdrawing it causes a deep feeling of incoherence. Kohut calls such moments "mini-fragmentations." Because fragmentation is so painful, patients seek relief from it immediately in characteristic ways.

The broadest and most obvious route to effect such repair is through hypersexualization. In phenomenological terms, hypersexualization seems especially attractive precisely because it permits one to establish an intense feeling of body integrity and wholeness, even if it is temporary. To speculate further, it seems likely that increased sexual excitation, especially orgasm, serves to concretize and validate the underlying unconscious fantasy. In male homosexual experience, for example, selfobject needs may be symbolized through the fantasy of incorporating the awesome power of father's penis and retaining it inside, as an actual structure or "backbone." In female homosexual experience, orgasm may often symbolize an actual merger with the mother's body and therefore instantiate her internal presence. In both instances Kohut permits us to account for the perverse action as attempts to use physical experience (orgasm) to replace temporarily psychological structure.

These are not radical psychoanalytic conclusions. Numerous ego psychologists have made similar comments about the fantasy structures underlying perverse (and normal) sexuality. Kohut's contribution has included the clinical insight that perversions, especially in narcissistically vulnerable patients, occur as the consequence of empathic failures. I think this is an extremely helpful point of view.

Kohut describes many such sequences in his texts. I suggest that we see an intergenerational sequence in Confessions. Monica's nurse exaggerates the danger (and power) of alcohol to her wards and so instills a lifelong fascination with wine that permeates Monica's character. The nurse's mistrust of the child's internal capacities represents a maternal failure. Indeed, it symbolizes her recognition of the young girl's intense "oral" need for nurture displaced onto alchohol. Hence her premonition of Monica's addiction, made manifest by her obsessive efforts to train her words to ignore normal thirst, guarantees precisely such dependency. Like the nurse, Monica and her son disdain those feelings and needs for an internalized "good object" (a selfobject) that would sustain her internally. Not accidently, these needs for ongoing maternal reflection of her narcissistic wishes become symbolized by the beverage, wine, which gives one a temporary sense of elation, power, and internal warmth. In this sense, Monica's addiction to wine and her son's addiction to hypersexual actions represent their responses to intergenerational failures. Nurse, mother, and son disdain these internal needs and seek to alienate themselves from part of themselves. Augustine calls such needs the product of a "despicable fault" (194).

This issue reappears in the dramatic conversation between mother and son which Augustine reports immediately following this account: "no bodily pleasure, however great it might be and whatever earthly light might shed lustre upon it, was worthy of comparison, or even mention, beside the happiness of the life of the saints" (197). Their conversation mounts in intensity and spiritual fervor: "At length we came to our own souls and passed beyond them to that place of everlasting plenty, where you feed Israel forever with the food of truth" Finally, "for one fleeting instant we reached out and tourhed 
it. Then with a sigh, leaving our spiritual harvest bound to it, we returned to the sound of our own speech, in which each word has a beginning and an ending." When a fleshly, human mother cannot provide a sense of inherent worthiness and narcissistic wholeness, God, the great mother who feeds Israel, will.

This passage precedes Augustine's account of his mother's death. Hence it looks forward to that immense loss and serves to prepare author and reader for it. Its overt message is that of a better life beyond this one, where words would not have a beginning and an ending, but the fleeting moment would last forever. I think it also looks back to the sharp denunciations of Monica's alcoholism and her son's life outside the true Church. Mother and son engaged in a kind of spiritual ecstasy that unifies them in a common bond of selfobject merger with God: "for all these things have the same message to tell, if only we can hear it, and their message is this: We did not make ourselves, but he who abides forever made us" (198).

From an analytic point of view, this immensely powerful notion of God's presence corresponds directly to the universal human need to find, somewhere, another who knows us to our depths, recognizes our faults, yet loves us completely. One might, using Kohut, therefore say that the debate between Augustine and Freud centers on the question of to what degree God is a selfobject, or God is a Wholly Other who has instilled in God's creatures an ineradicable longing to see their creator face to face.

\section{REFERENCES}

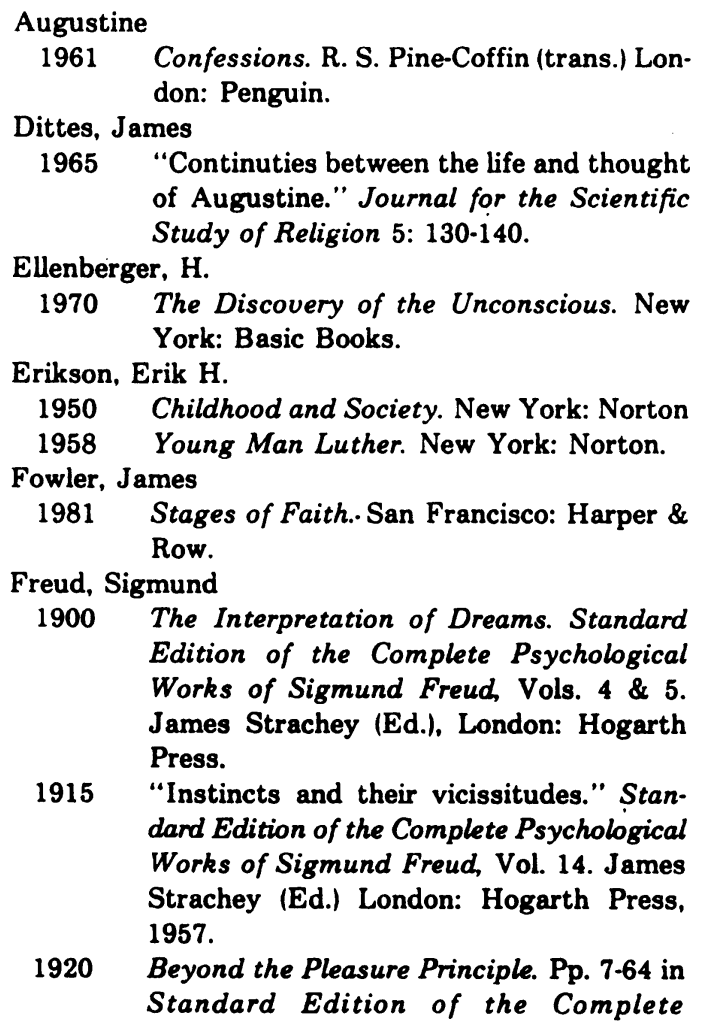

1915 "Instincts and their vicissitudes." Standard Edition of the Complete Psychological Works of Sigmund Freud, Vol. 14. James Strachey (Ed.) London: Hogarth Press, 1957.

1920 Beyond the Pleasure Principle. Pp. 7-64 in Standard Edition of the Complete Ego. Pp. 69-133 in Standard Edition of the Complete Psychological Works of Sigmund Freud, Vol. 18. James Shachey (Ed.) Lon- don: Hogarth Press, 1955.

1921 Group Psychology and the Analysis of the

Gide, A.

1967 Journals 1889-1949. J. O'Brien (Ed. and trans.) London: Penguin.

Goethe, J. W.

1811. Truth and Fiction. Trans. John Oxenford 1833 (Trans.) The Weimar Edition, n.d.

James, William

1902 The Varieties of Religious Experience. New Kaplan, L. York: Collier Books, 1961.

1961 Bibliography of American Autobiography. Madison: University of Wisconsin.

\section{Kohut, Heinz}

1959 "Introspection, empathy, and psychoanalysis." Journal of the American Psychoanalytic Association 7: 459-83.

1966 "Forms and transformations of narcissism." Journal of the American Psychoanalytic Association 14: 243-72.

1972 "Thoughts on narcissism and narcissistic rage." The Psychoanalytic Study of the 
Child 27: 360-400.

1977 The Restoration of the Self. New York: International Universities Press.

1984 How Does Analysis Cure? Chicago: The University of Chicago Press.

Kohut, H. and E. S. Wolf

1978 "The disorders of the self and their treatment: An Outline." International Journal of Psycho-Analysis 59: 413-25.

Rousseau. Jean Jacques

1781- The Confessions of Jean Jacques 1788 Rousseau.

Tausk, Victor

1919 "On the origin of the "influencing machine" in schizophrenia." Psychoanalytic Quarter ly 2: 519-56.
TeSelle, Eugene

1970 Augustine the Theologian. New York. Herder and Herder.

Tolstoy, Leo

1983 Confessions. D. Patterson (Trans.). New York: Norton.

Wisdom, John

1967 "Testing an interpretation within a session." International Journal of PsychoAnalysis 48: 44-52.

Wittgenstein, Ludwig

1958 Philosophical Investigation. 3rd Ed. G. E. M. Anscombe (Trans.). New York: Macmillan. 